\title{
High Capacity Variable Friction Damper based on Band Brake Technology
}

\author{
Austin Downey ${ }^{\mathrm{a}, \mathrm{d}}$, Liang $\mathrm{Cao}^{\mathrm{a}}$, Simon Laflamme ${ }^{\mathrm{a}}$, Douglas Taylor ${ }^{\mathrm{b}}$, James \\ Ricles $^{\mathrm{c}}$ \\ ${ }^{a}$ Department of Civil, Construction, and Environmental Engineering, Iowa State \\ University, Ames, IA 50011, USA \\ ${ }^{b}$ Taylor Devices, North Tonawanda, NY 14120, U.S.A \\ ${ }^{c}$ Department of Civil and Environmental Engineering, Lehigh University, Bethlehem, PA \\ 18015, U.S.A \\ ${ }^{d}$ Corresponding author, e-mail: adowney2@iastate.edu
}

\begin{abstract}
Implementation of high performance controllable damping devices can ameliorate cost-effectiveness of structural systems for mitigation of natural hazards. However, the applications of these damping systems are limited due to a lack of 1) mechanical robustness; 2) electrical reliability; and 3) large resisting force capability. To broaden the implementation of modern damping systems, a novel semi-active damping device is proposed. The device, termed Banded Rotary Friction Device (BRFD), has enhanced applicability compared to other proposed damping systems due to its cost-effectiveness, high damping performance, mechanical robustness, and technological simplicity. Its mechanical principle is based on a band brake, which results in a high amplification of the applied force while enabling a variable control force. The theoretical model of the BRFD is presented and experimentally verified by subjecting a prototype to various harmonic loads. Results show that the prototype BRFD is capable of a maximum force of $45 \mathrm{kN}$ (10 kips) using only
\end{abstract}


a $267 \mathrm{~N}(60 \mathrm{lb})$ actuation force, therefore providing a mechanical advantage of 169. A 3-stage dynamic model previously developed by the authors can successfully be used to model the dynamic behavior of the BRFD.

Keywords: Variable friction, semi-active device, structural control, vibration mitigation, supplemental damping, modified friction device

\section{Introduction}

2

Passive supplemental damping devices have become widely accepted in structural engineering for natural hazard mitigation $[1,2]$. However, they are typically only applicable to a limited bandwidth of excitations because their damping forces cannot be varied post manufacturing. Active dampers are possible alternatives to provide higher mitigation performance. Nevertheless, they require large external power sources that may not be available during or after a natural hazard, have the potential to destabilize a system, and can be expensive to operate during sustained wind events [3].

Semi-active damping strategies combine some of the benefits of passive and active strategies [4]. They are purely reactive systems, in the sense that they cannot add energy to the control system, and can alter their mechanical properties to provide additional controllability using a fraction of the power required by active strategies. Semi-active devices are divided into four classes: variable stiffness [5, 6], variable orifices [7], variable fluid [8] and variable friction [9] devices. 
In particular, variable friction devices are capable of high energy dissipation, independent of velocity by dissipating mechanical energy into heat via a friction force that is controlled by an actuator with a varying normal force. Examples of actuators used in variable friction devices include: pneumatic $[10,11]$, hydraulic [12], electro-magnetic [13, 14], electro-mechanical [15, 16] and piezoelectric $[17,18,19,20]$. This controllability of the normal force minimizes obstacles found in passive friction devices, namely, the response produced by the strong nonlinear behavior, degradation of sliding interface, and cold weld $[21,2]$.

Literature cites several examples of working variable friction prototypes for structural control applications. A semi-active independently variable friction device possessing a $25 \mathrm{kN}$ (5.5 kips) maximum damping force provided by an electromechanical actuator has been experimentally verified [15]. Others $[18,22]$ have investigated piezoelectric friction devices (PFD) of $0.5 \mathrm{kN}$ (2.2 kips) and $25 \mathrm{kN}$ (5.5 kips) damping force capacity, respectively. An electromagnetic friction damper device (EFD) having a $2.84 \mathrm{kN}$ (0.64 kips) damping force capacity has also been developed [23].

Despite these efforts to produce semi-active friction devices suited for structural control applications, combined with studies demonstrating their economic advantages over passive systems, (see [24, 25, 26]), their implementation has remained limited. This could be due to low damping capability and the availability of mechanically reliable technologies [27]. 
In an effort to provide both high damping capacity and high mechanical reliability, the authors have recently proposed a variable friction device based on automotive dual servo drum brake technology. The technology, termed the Modified Friction Device (MFD) was theoretically presented and a prototype fabricated and demonstrated [27]. While the prototype was a small scale version constructed from a $200 \mathrm{~mm}$ (8 in) automotive duo-servo drum brake, a key feature found in the experimental verification was a discontinuity of the friction dynamics when the rotation reversed due to the internal layout of the braking shoes and bracing pins. This discontinuity led to a sharp reduction in the damping force provided during a substantial portion of a damping cycle. Under specific conditions of limited displacement, the damper was found to provide very limited damping force, irrespective of the applied force. The maximum damping force obtained from the prototype was $3.1 \mathrm{kN}(0.7 \mathrm{kip})$.

The objective of this paper is to introduce a second generation of rotary variable friction devices with substantially enhanced applicability to mitigation of structural vibrations. This second generation device is designed to be capable of producing a damping force of one order of magnitude higher while overcoming the limitations found in the dynamics of the MFD and preserving a simple and mechanically robust design. This novel device, presented for the first time, is based on band brake technology, and is termed Banded Rotary Friction Device (BRFD). Band brakes have been used in mining and marine mooring applications for decades [28, 29] and have proven to be a mechanically robust technology [30]. Their maintenance costs are known 
to be limited due to their simple mechanics, no internal parts or hydraulic fluid, and the easy replacement/availability of friction material [31]. In this paper, the BRFD is introduced, and a working prototype is experimentally verified. The 3-stage dynamic model developed by the authors [27] is used to characterize its behavior.

The paper is organized as follows. The next section introduces the BRFD and provides its theoretical background. This is followed by a presentation of a 3-stage dynamic model used in the characterization of the device's dynamic behavior. The subsequent section discusses the experimental methodology and the prototyping of the BRFD, along with a presentation and discussion of the experimental results. The last section concludes the paper by providing a summary of the findings.

\section{Banded Rotary Friction Device}

The BRFD utilizes existing band brake technology. A band brake is a robust and reliable friction brake consisting of a flexible band lined with friction material that tightens concentrically around a cylindrical drum to slow or stop its rotation. The BRFD is a double band brake system, consisting of a band lined with a friction material [31], doubled wrapped around a drum, as shown in Fig. 1a. It is capable of providing variable braking torques as a linear function of an applied force, which is significantly amplified by the brake's positive servo effect.

A $45 \mathrm{kN}$ (10 kips) capacity prototype was fabricated based on the schematic 
shown in Fig. 1a. The flat double wrap band is illustrated in Fig. 1b. The band is lined with friction material and wrapped 670 degrees around the circumference of the steel drum and anchored at both ends. The single end of the band is attached to an actuation mechanism consisting of a threaded rod for the purpose of varying the force applied to the band brake, and the double end of the band is anchored to the rigid frame. The prototype has been designed to be installed within a structural bracing scheme. Such an implementation scheme is discussed below.

\subsection{Implementation within a Structural System}

The BRFD is designed to transform displacement into rotation, $\theta$. The device can therefore be integrated within a multiplicity of structural control schemes, including hybrid base-isolation systems, semi-active tuned mass dampers, and bracing elements. Fig. 2 shows the BRFD installed in two possible configurations associated with a building lateral load resisting system. Fig. 2(a) is a chevron system that transduces interstory drift $\delta$ into rotation $\theta$ of the BRFD via the addition of a connecting link. Fig. 2(b) is a toggle bracing configuration. The toggle bracing is used in structural motion engineering to amplify the interstory drift [32]. While more expensive than a typical chevron system, a toggle bracing system allows the BRFD to reach a maximum frictional force faster and reduce the heat intensity on the friction material, thus increasing the mitigation performance of the device. In both configurations the inter story $\operatorname{drift} \delta=x / H$, where $x$ and $H$ are the lateral displacement of the floor and the story height, respectively. An expression for the linear displacement $y$ can be written as 


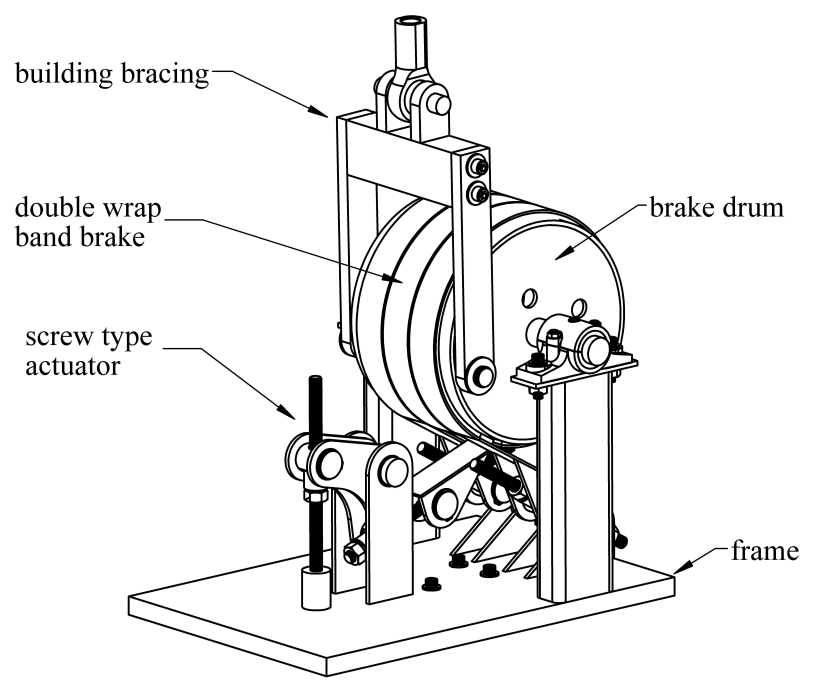

(a) double wrap band brake system

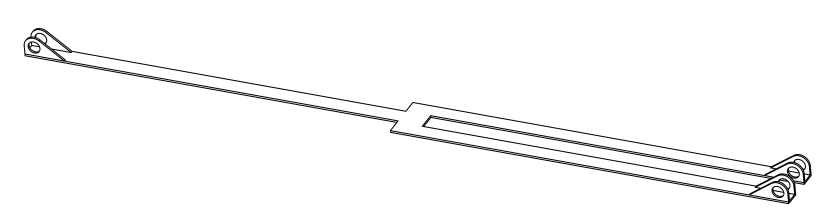

(b) double wrap band brake

Figure 1: banded rotary friction device 


$$
y=\theta \cdot r_{b}
$$

118

where $r_{b}$ is the distance from the center of the drum to the brace connection. For the chevron configuration where $y=x$ the rotation can be derived as

$$
\theta=\frac{\delta \cdot H}{r_{b}}
$$

For the toggle configuration, assuming small displacements, it can be shown that [33]

$$
y=\frac{\sin (\alpha)}{\cos (\alpha+\beta)} \cdot x
$$

and

$$
\theta=\frac{\sin (\alpha)}{\cos (\alpha+\beta)} \frac{\delta \cdot H}{r_{b}}
$$

Eqs. (2) and (4) can be used in a performance-based design procedure [3]. The following section derives the equations governing the BRFD friction mechanism.

\subsection{Friction Mechanism}

The friction force of the BRFD is generated by the drum rotating through the stationary band. The band is anchored at one end (called the slack end), where an input force $\left(F_{\text {applied }}\right)$ is applied to the band, resulting in a reactionary force $\left(F_{\text {reaction }}\right)$ at the opposite end, as shown in Fig. 3. When rotation of the drum is initiated, a friction force $\left(F_{\text {friction }}\right)$ is generated opposing the rotation of the drum at the interface between the friction material and the drum. This force causes the band to experience an elastic deformation 


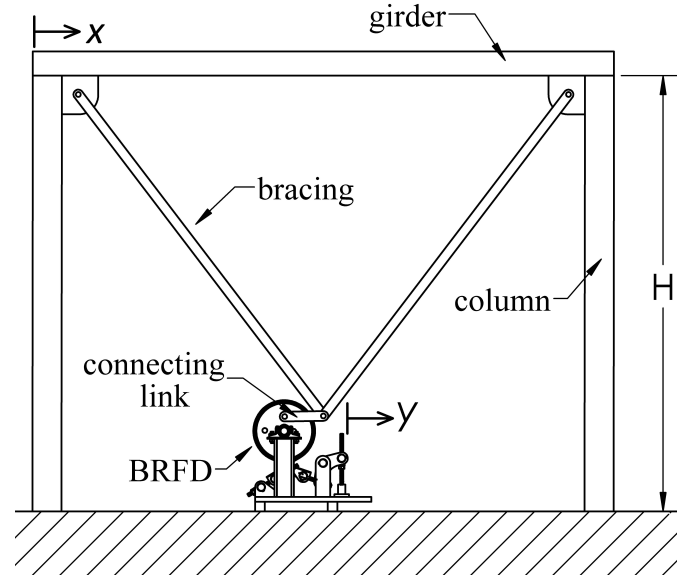

(a) chevron configuration

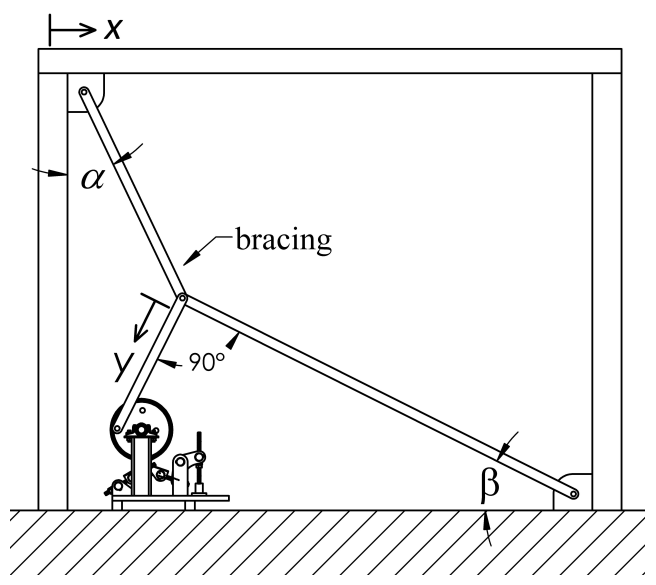

(b) toggle configuration

Figure 2: Two possible configurations for the BRFD installed within a building's lateral load resisting structural system.

and displacement in the direction of the drum rotation. The forces present in the band are expressed as, [34]

$$
F_{\text {reaction }}=F_{\text {friction }}+F_{\text {applied }}
$$

As the tension in the band increases towards the pinned end, the band wraps tightly around the drum, creating the positive servo effect, also known as the self-energizing effect. This phenomenon increases the contact pressure of the friction material linearly with respect to the angular displacement from the point of the applied force on the drum [34]. The continuously changing contact pressure between the band and the drum is shown in Fig. 3. The contact pressure increases uniformly from $p_{0}$ to $p_{\max }$. 

158

For the mathematical model it is assumed that the drum surface has a uniform curvature and the band conforms evenly to the drum surface. The initial asymmetry due to the elastic deformation of the band material is not considered. The forces $F_{\text {applied }}, F_{\text {reaction }}$ and $F_{\text {friction }}$ can be related to each other as follows. The relationship between the forces acting on the band ends ( $F_{\text {applied }}$ and $\left.F_{\text {reaction }}\right)$ is expressed as

$$
F_{\text {reaction }} / F_{\text {applied }}=e^{\mu \phi}
$$

where $\phi$ and $\mu$ represent the band wrap in radians and the friction coefficient of the friction material, respectively. Equations 5 and 6 can be combined to show

$$
\begin{gathered}
F_{\text {reaction }}=\frac{F_{\text {friction }} \cdot e^{\mu \phi}}{\left(e^{\mu \phi}-1\right)} \\
F_{\text {applied }}=\frac{F_{\text {friction }}}{\left(e^{\mu \phi}-1\right)}
\end{gathered}
$$

53 It can be noted from Eq. (5) that the friction force $F_{\text {friction }}$ is independent of the drum radius $r$. However, a braking torque $T$ can be expressed as $T=F_{\text {friction }} \cdot r$. This braking torque is used to generate a damping force, $F_{\text {damping }}$

$$
F_{\text {damping }}=\frac{T}{r_{b}}=\frac{F_{\text {friction }} \cdot r}{r_{b}}
$$

157 where $F_{\text {damping }}$ is the force applied to the bracing element. From Eq. (9), the device's mechanical advantage $C$ is derived as: 


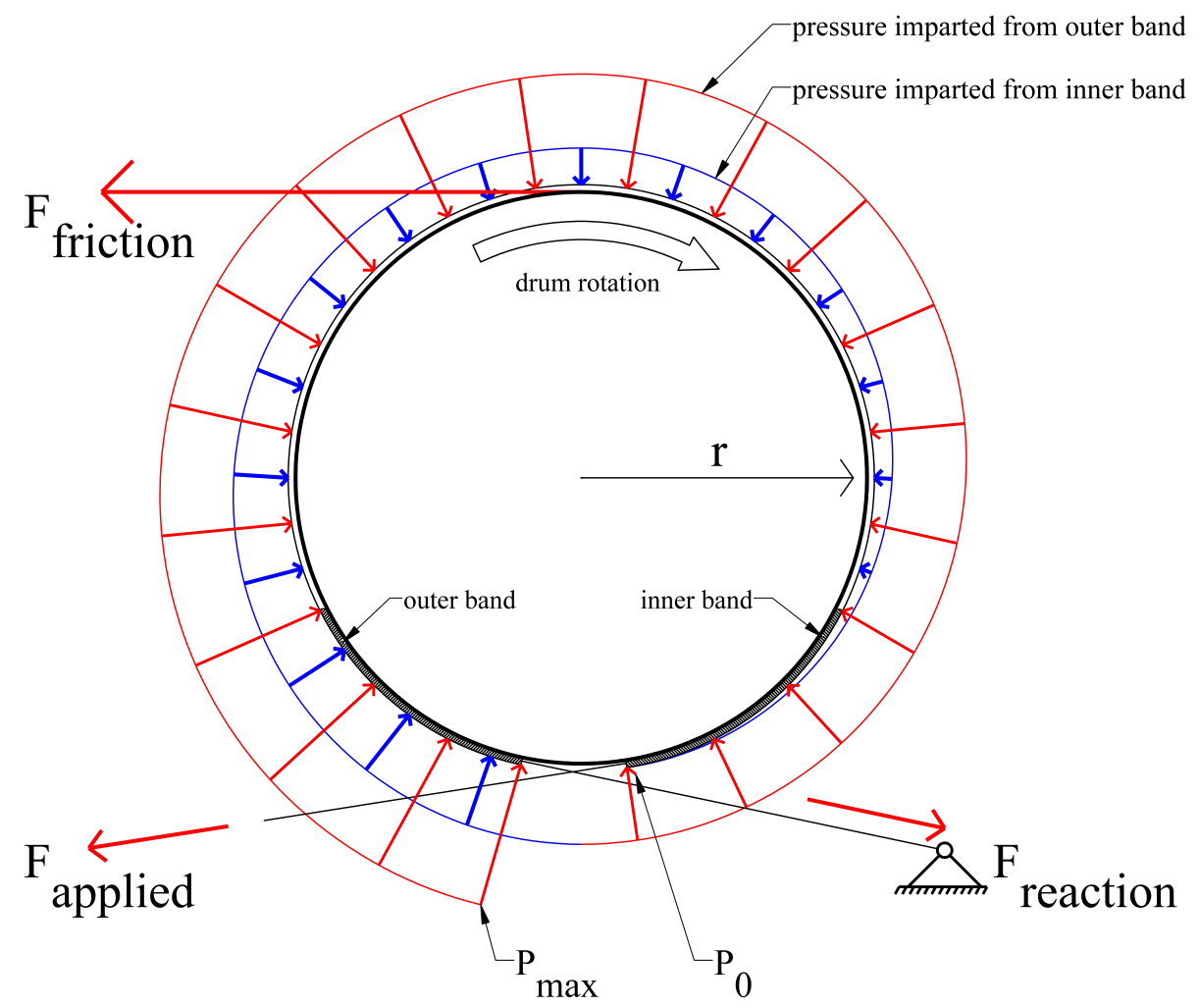

Figure 3: Forces acting on the BRFD

$$
C=\frac{F_{\text {damping }}}{F_{\text {applied }}}=\left(e^{\mu \phi}-1\right) \cdot\left(\frac{r}{r_{b}}\right)
$$

where $F_{\text {damping }}>F_{\text {applied }}[35]$. The mechanical advantage $C$ is a function of the constants $\phi$ (expressed in radians), $\mu, r$ and $r_{b}$, which are determined during the device's design process. It follows that $F_{\text {damping }}$ is a linear response of $F_{\text {applied }}$ amplified by the constant $C$.

A schematic of the side view of the BRFD is shown in Fig. 4, where forces $\mathrm{w}_{1}$ and $\mathrm{w}_{2}$ can be either $\left(F_{\text {applied }}\right)$ or $\left(F_{\text {reaction }}\right)$ depending on the direction of 


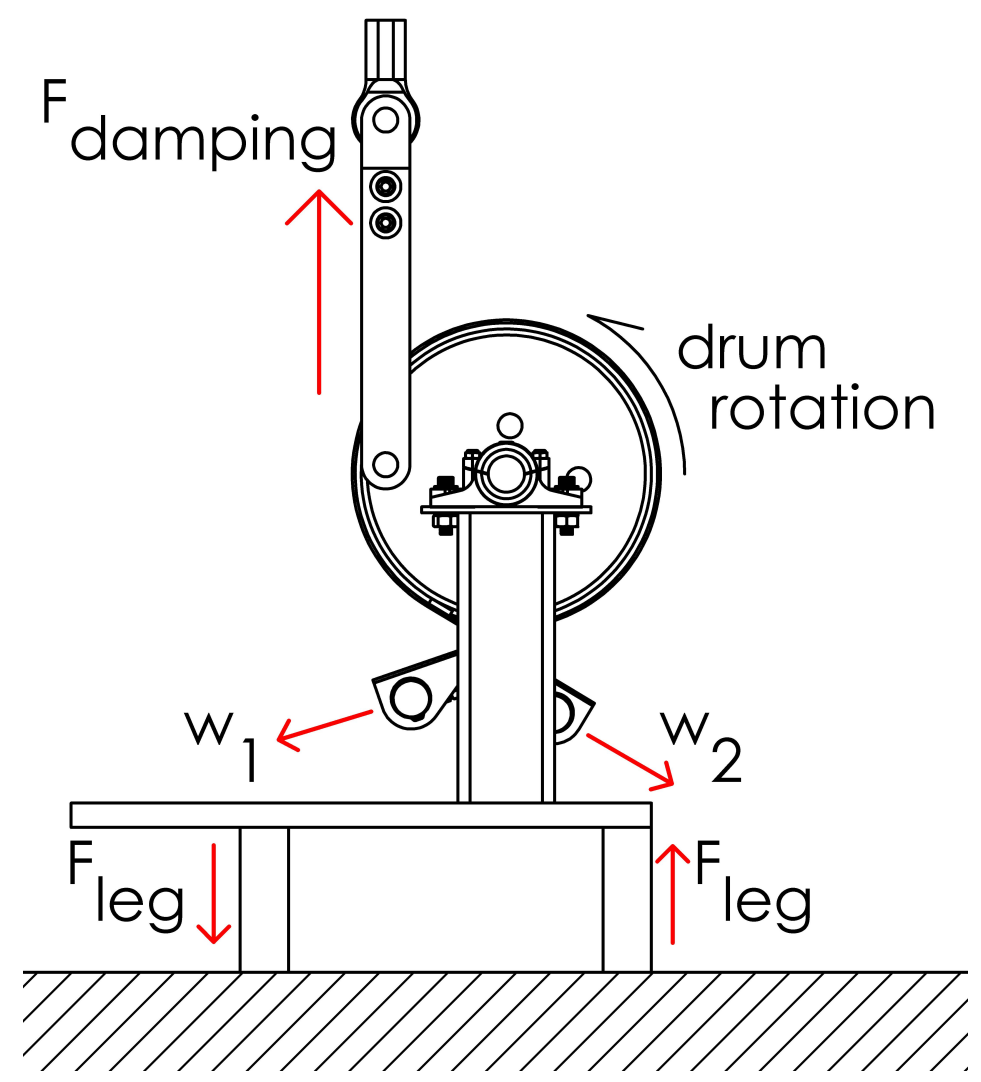

Figure 4: Schematic of the side view of the BRFD

rotation of the drum. This design implementation allows for the damper to take advantage of the positive servo effect in both directions of rotation. The BRFD is designed to sit on two support legs that produce opposite forces $F_{\text {leg }}$ that counteracts the moment produced by the friction forces on the drum.

\section{Dynamic Model}

The authors have previously proposed a 3-stage dynamic model based on a modified LuGre model [27] for characterizing the friction behavior of the first generation of a rotary damping device (i.e., the MFD). This particular 
dynamic model was useful at characterizing the drop in force that occurs when the rotation of the drum is reversed. As it will be observed in the experimental results presented herein, the BRFD still exhibits a small drop in force upon reversal and the 3-stage dynamic model therefore still applies. This can be observed in Fig. 5 under "stage 2". This drop in the force is a product of the rearrangement of the device's components and forces caused by the change in direction of the brake drum, termed backlash. Four major sources of backlash in the BRFD prototype are as follows:

1. Elastic deformation of the band that occurs during the initial drum rotation.

2. Deviations of the band from an ideal uniform curvature encasing the drum, causing non-uniformed strain in the metal band;

3. Excess curvature present were the band connects to the supporting linkage. The curvature of the band in the connecting region changes when the force changes from $\left(F_{\text {applied }}\right)$ to $\left(F_{\text {reaction }}\right)$, resulting in a changing chord length. This phenomenon can be seen in Fig 7 .

4. Deflection of the base and legs supporting the rotating drum.

The 3-stage dynamic model allows for the accurate modeling of the hysteretic behavior, including the stiffness region developed by the BRFD's backlash. Fig. 5 illustrate the three different stages through a plot of a typical dynamic response of the BRFD extracted from the experimental results under a harmonic displacement input of $25.4 \mathrm{~mm}$ ( 1 in) amplitude, divided into 3 stages: 
- Stage 1 (location $1 \longrightarrow$ location 2 ) - The system is in a typical dynamic friction mode. The friction force associated with this stage, $\left(F_{1}\right)$, is characterized using a LuGre friction model. This stage occurs until rotation is reversed and the frictional force is lost.

- Stage 2 (location $2 \longrightarrow$ location 3 ) - The linear force $F_{2}$, associated with Stage 2 is characterized as being proportional to a stiffness element $k_{2}$. This stage occurs over a drum displacement $d_{2}$. The length of this stage is governed by the amount of backlash present in the device.

- Stage 3 (location $3 \longrightarrow$ location 1 ) - The force $F_{3}$ associated with this stage is characterized as being proportional to a stiffness element $k_{3}$. This stage occurs over a drum displacement $d_{3}$, after the backlash gap has been taken up by the rotating drum.

The LuGre friction model was selected to characterize the device's friction mode due to its capacity to model the stick-slip motion and the Stribeck effect [36]. The LuGre model has been applied to a wide range of systems due to its computational simplicity [37, 38, 39, 40]. Under this model, the friction force is written

$$
F_{\text {friction }}=\sigma_{0} z+\sigma_{1} \dot{z}+\sigma_{2} \dot{\zeta}
$$

where,

$$
\dot{z}=\dot{\zeta}-\sigma_{0} \frac{|\dot{\zeta}|}{g(\dot{\zeta})} z
$$

where $\sigma_{0}$ is a constant representing the aggregate bristle stiffness, $\sigma_{1}$ is the microdamping, $\sigma_{2}$ is the viscous friction, $z$ is an evolutionary variable, $\dot{\zeta}$ is 


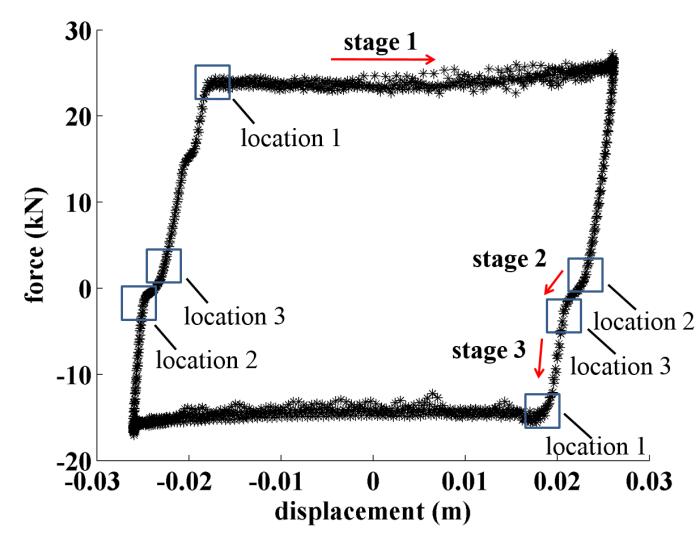

(a)

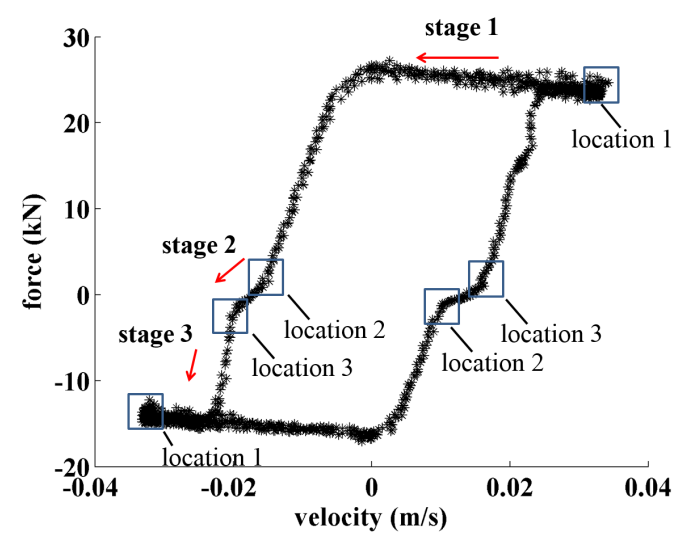

(b)

Figure 5: Dynamic response of the BRFD under applied force of $133 \mathrm{~N}$ (30 lb) : (a) force-displacement hysteretic response $(0.2 \mathrm{~Hz})$; and (b) force-velocity hysteretic response $(0.2 \mathrm{~Hz})$.

the BRFD's surface displacement and velocity, and $g(\dot{\zeta})$ is a function used to describe the Stribeck effect

$$
g(\dot{\zeta})=F_{c}+\left(F_{s}-F_{c}\right) e^{-\left(\frac{\dot{\zeta}}{\dot{x}_{s}}\right)^{2}}
$$

where $\dot{x}_{s}$ is a constant representing the Stribeck velocity, $F_{s}$ is the static friction force, and $F_{c}$ the kinetic friction force. $F_{s}$ is taken when the velocity of the device $\dot{\zeta}=0$, and $F_{c}$ taken as the steady state force (when $\dot{\zeta} \gg x_{s}$ ). In Eq. $(10), \zeta \approx \theta \cdot r$.

A smoothing function is introduced to the transition region between each dynamic stage. It consists of a $C^{\infty}$ function of the following type [41]:

$$
m(\zeta)=\frac{1}{1+e^{-\frac{\gamma_{1}\left(\zeta-\zeta_{0}\right)}{\gamma_{2}}}}
$$


where $\zeta_{0}$ is the reference displacement of the new stage, and $\gamma_{1}, \gamma_{2}$ are constants. For instance, the total force $F$ during the transition from stage $i$ to stage $j$ is written

$$
F=(1-m(\zeta)) F_{i}+m(\zeta) F_{j}
$$

where $F_{i, j}$ is the total force computed using the definition of stage $i, j$. Remark: the amplitude of the damping force of the prototype is not symmetric as a function of the rotational direction. This can be explained by the asymmetries in the friction material and band. A proper break-in procedure should significantly reduce or eliminate the unsymmetrical damping dynamics. This is out-of-the-scope of this paper. Here, the static and dynamic friction force coefficients are separated between forward $\left(F_{s, \text { fwd }}\right.$ and $\left.F_{c, \text { fwd }}\right)$ and backward $\left(F_{s, \text { bwd }}\right.$ and $\left.F_{c, \text { bwd }}\right)$ force components.

\section{Experimental Validation}

\subsection{Prototype}

A prototype of the BRFD from the schematic shown in Fig. 1a was fabricated to verify its performance at producing high damping forces. Friction material used was flexible, asbestos-free, woven yarn material with copper wire [31]. The design parameters are listed in Table 1. A photograph of the prototype is shown in Fig. 6.

\subsection{Methodology}

The prototype BRFD was mounted in a servo-hydraulic testing machine and its characterization performed. Applied forces where controlled through 
Table 1: Design parameters of the BRFD prototype

\begin{tabular}{lc}
\hline Parameter & Value \\
\hline Drum diameter & $0.30 \mathrm{~m}$ (12 in) \\
Damping radius $\left(r_{b}\right)$ & $0.10 \mathrm{~m}$ (4 in) \\
Drum material & A-53 steel \\
Total band brake length & 2.13 meters (84 in) \\
Band thickness & 3.2 mm ( $1 / 8$ in $)$ \\
Band material & A-36 steel \\
Friction material & Woven, asbestos-free \\
Coefficient of friction $(\mu)$ & 0.39 \\
Band brake wrap $(\phi)$ & $670^{\circ}$ \\
Mechanical advantage $(C)$ & 142 \\
\hline
\end{tabular}




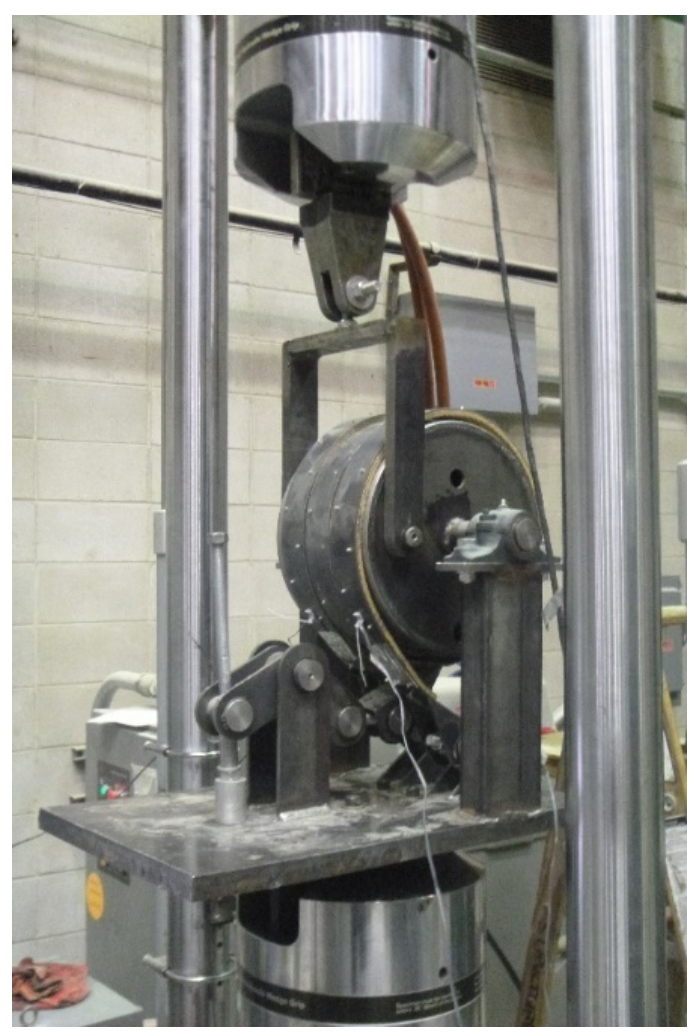

Figure 6: BRFD testing setup

a screw-activated tensioner attached to one side of the band. A load cell was placed between the BRFD's frame and the activation mechanism for measuring the applied forces. The damping force generated by the BRFD was measured via a load cell located in the head of the testing machine. The test setup is shown in Fig. 6, with the BRFD in its fully un-actuated position. The testing of the BRFD was limited to its designed $45 \mathrm{kN}$ (10 kips) damping force capacity.

The prototype was subjected to displacement-controlled harmonic excitations of $25.4 \mathrm{~mm}$ (1 in) amplitude at four different frequencies: 0.05, 0.1, 0.2 , and $0.5 \mathrm{~Hz}$. Five different applied forces $\left(F_{\text {applied }}\right)$ were investigated: 35 
(8), $53(12), 66(15), 133(30)$ and $267 \mathrm{~N}$ (60 lbs), where $35 \mathrm{~N}$ (8 lbs) is the minimum force available from the actuation mechanism and $267 \mathrm{~N}$ (60 lbs) corresponds approximately to the prototypes maximum capacity. A total of 20 tests were performed.

\subsection{Model Parameters}

The 3-stage dynamic model parameters were identified by minimizing the performance function $J$, consisting of the fitting error between the estimated force from the model $\hat{F}_{\text {friction }}$ and experimental data $F_{\text {friction }}$ for each test $k$ :

$$
J_{k}=\left\|\hat{F}_{\text {friction, } k}-F_{\text {friction, } k}\right\|_{2}
$$

where $\|\cdot\|_{2}$ is the 2 nd Euclidean norm. This minimization was conducted in MATLAB by using the command fminsearch under various arbitrary (and physically realistic) initial conditions. Model parameters dependent on the applied force $\left(F_{\text {applied }}\right)$ are the static friction $F_{s}$, the dynamic friction $F_{c}$, and the aggregate bristle stiffness $\sigma_{0}$.

Table 2 lists the average values of the applied force dependent model parameters, obtained from the experimental results. These average values exhibit a linear and amplified response to the applied forces. This linearity would typically be modeled and used in a model fitting task. However, due to the medium fidelity of the developed prototype, test results experienced some irregularities. These irregularities are likely caused by deviations of the band 
Table 2: applied force dependent model parameters

\begin{tabular}{lccccc}
\hline & \multicolumn{5}{c}{$F_{\text {applied }}$} \\
\cline { 2 - 6 } Parameter & $35 \mathrm{~N}$ & $53 \mathrm{~N}$ & $66 \mathrm{~N}$ & $133 \mathrm{~N}$ & $267 \mathrm{~N}$ \\
\hline$F_{c, \text { fwd }}(\mathrm{kN})$ & 0.805 & 1.91 & 13.3 & 22.7 & 37.3 \\
$F_{c, \text { bwd }}(\mathrm{kN})$ & 0.538 & 0.521 & 3.11 & 13.4 & 37.8 \\
$F_{s, \text { fwd }}(\mathrm{kN})$ & 0.894 & 2.23 & 14.2 & 23.6 & 39.1 \\
$F_{s, \mathrm{bwd}}(\mathrm{kN})$ & 0.619 & 0.579 & 3.33 & 14.2 & 44.5 \\
$\sigma_{0}\left(\mathrm{kN} \cdot \mathrm{m}^{-1}\right)$ & 525 & 613 & 1490 & 5694 & 9198 \\
\hline
\end{tabular}

from an ideal uniform curvature, and bending in the BRFD's frame. These constraints are not inherent to the devices' architecture and would be eliminated in a high fidelity prototype or production model. With the current discrepancies and the relativity low number of characterization tests performed, a linear fit of the results produces a high level of error on the estimation of the parameters. Therefore, a function of the type $F_{(c, s),(\mathrm{fwf}, \mathrm{bwd})}=f\left(F_{\text {applied }}\right)$ is out of the scope of this work.

The mechanical advantage $C$ can be directly calculated by using $F_{c}$ values from Table 2 as $F_{\text {damping }}$ in Eq. (10) . However, given the variability in the data explained above, there would be an important variability in the experimental $C$ computed for each test. To serve as a preliminary comparison with theory, it is best to use the values at the highest level of the applied forces, for which the band brake is the tightest and its angle is the most constant. For instance, Fig. 7 shows the changing band tension for applied 
forces of 35, 66, and $267 \mathrm{~N}$. The change in force results in a change in the gap between the friction material on the bands and the drum, this changing distance is exhibited in Fig. 7a through Fig. 7c. These changes are a function of the forces applied to the band. These frames were taken while the drum was in a backwards (clockwise) rotation, where the two exterior bands are acting as the fixed or reactionary ends.

Table 3 list the $C$ values for the forward rotation $\left(C_{\mathrm{fwd}}\right)$ and backward rotation $\left(C_{\mathrm{bwd}}\right)$ of the drum, along with the experimental friction coefficient $\mu$ derived using Eq. (10) for both rotational directions. The experimental results show an agreement with the design value of $C$ and the materials properties provided by the manufacturer $(\mu)$. The lower $C$ value for the backward rotation may be attributed to the asymmetries in the metal band and the adhered friction material.

Table 3: Validation of design parameters

\begin{tabular}{lcc}
\hline Parameter & test value & design value \\
\hline$C_{\text {fwd }}$ & 145 & 142 \\
$C_{\text {bwd }}$ & 126 & 142 \\
$\mu_{\text {fwd }}$ & 0.42 & 0.39 \\
$\mu_{\text {bwd }}$ & 0.41 & 0.39 \\
\hline
\end{tabular}

\subsection{Assessment of Model Accuracy}

Fig. 8 and 9 show plots of the experimental data fitting with the 3 -stage model for 0.05 and $0.50 \mathrm{~Hz}$ excitations, respectively, under various levels 


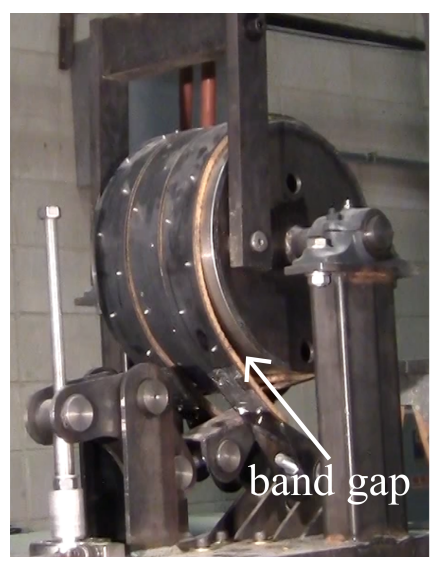

(a)

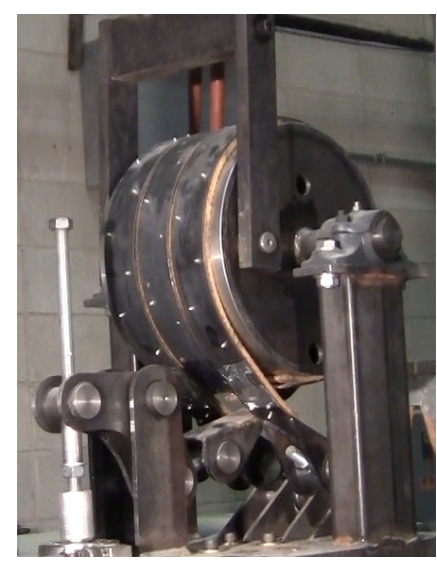

(b)

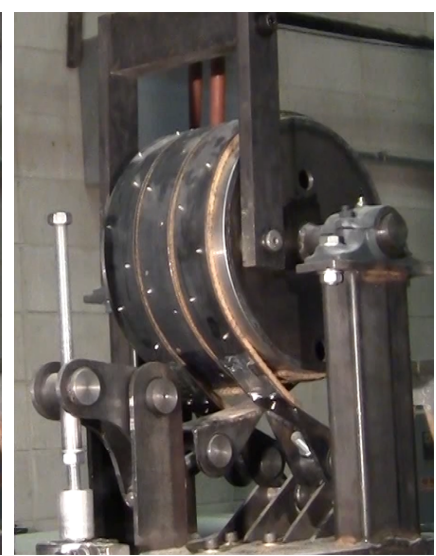

(c)

Figure 7: Band gap varying with the applied forces, (a) $35 \mathrm{~N}$; (b) $66 \mathrm{~N}$; (c) $267 \mathrm{~N}$;

of $F_{\text {applied }}(35,53,66,133$, and $267 \mathrm{~N})$. The model shows good agreement with the experimental data for all of the applied forces. There is a loss in fitting performance at the higher frequencies due to chattering in the device. Another observation in the $0.50 \mathrm{~Hz}$ excitation data is an unmodeled hump that occurs with a change in the rotational direction of the brake drum, for the case of a maximum applied force $(267 \mathrm{~N})$, and is less apparent at 133 $\mathrm{N}$. This hump is likely due to slippage of the the friction material due to deviations in the brake band. Fig. 10 compares the responses under various excitation frequencies under a $133 \mathrm{~N}$ applied force. Results are typical of other applied forces. The model shows good agreement with the experiment data for all frequencies, with a decrease in the fitting performance at the larger frequencies. This is consistent with the previous results.

Table 4 reports the root mean square error (RMSE) between the model prediction and experimental data results. Results are also compared with a 


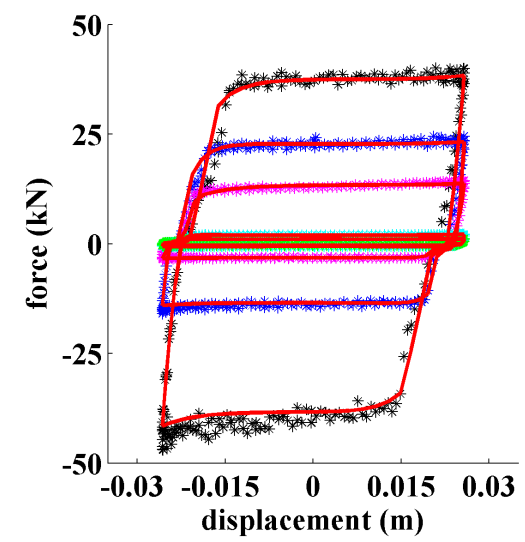

(a)

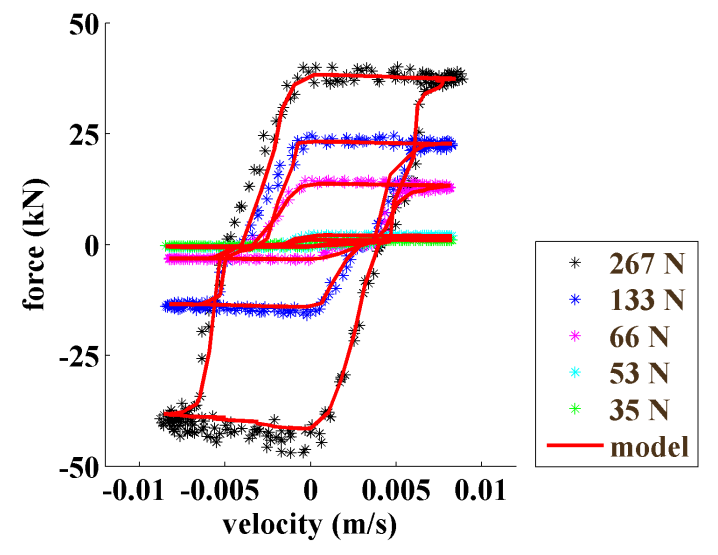

(b)

Figure 8: Experimental data fitting under various levels of applied forces for a $0.05 \mathrm{~Hz}$ excitation: (a) force-displacement; (b) force-velocity plots.

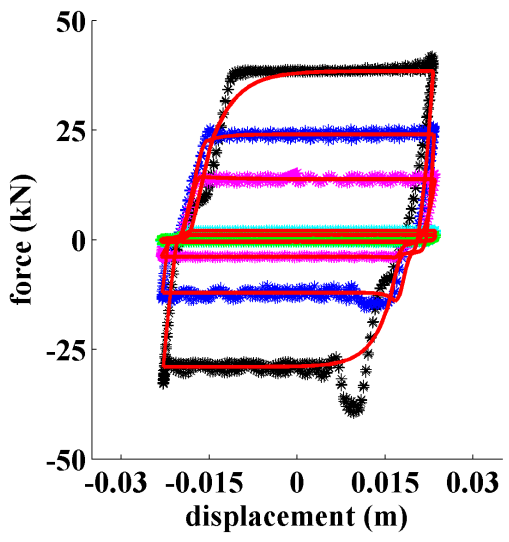

(a)

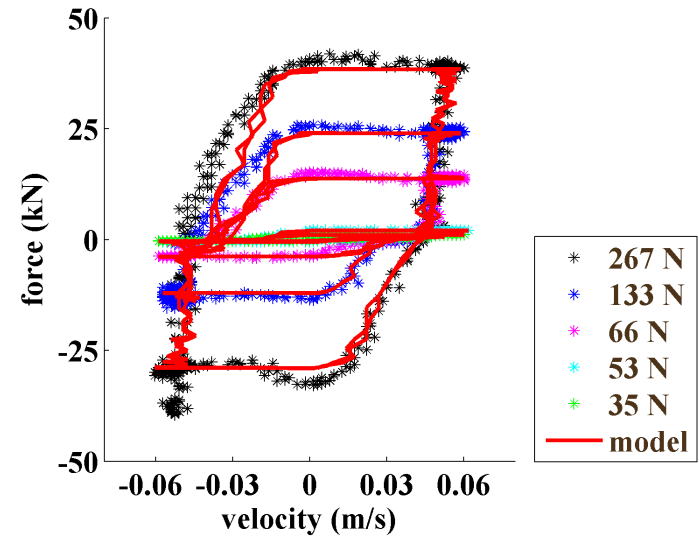

(b)

Figure 9: Experimental data fitting under various levels of applied forces for a $0.50 \mathrm{~Hz}$ excitation: (a) force-displacement; and (b) force-velocity plots. 


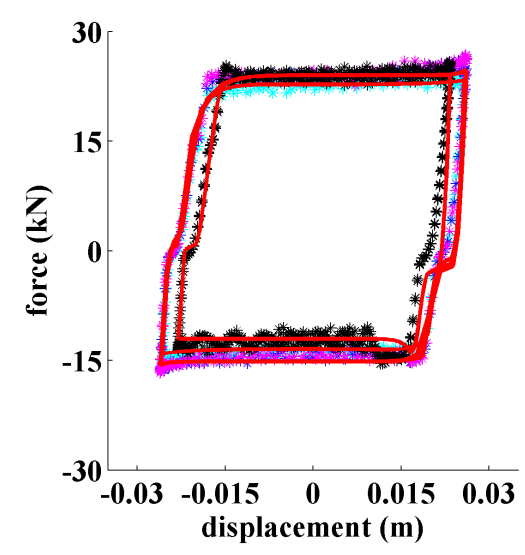

(a)

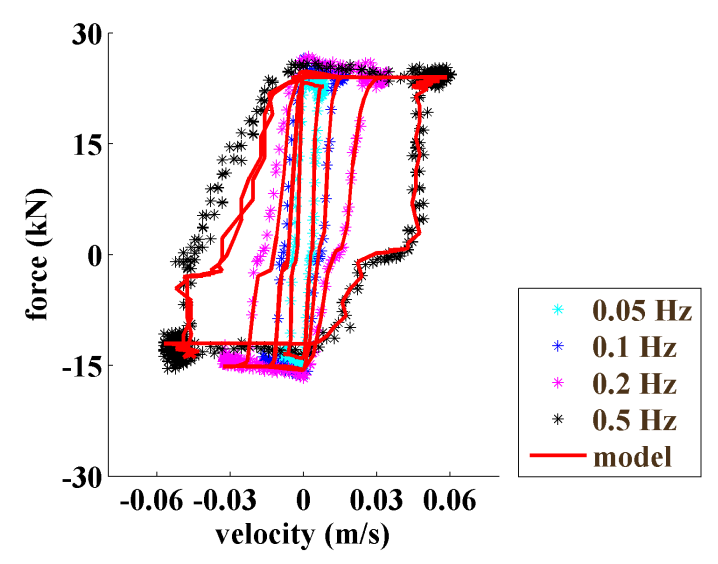

(b)

Figure 10: Experimental data fitting under various excitation frequencies for a $133 \mathrm{~N}$ (30 lbs) applied force: (a) force-displacement; and (b) force-velocity plots.

pure LuGre friction model optimized following a similar methodology used to identify the parameters for the 3-stage dynamic model. The listed RMSE confirm the performance of the 3-stage dynamic model discussed above. The pure LuGre model shows similar performance under a $53 \mathrm{~N}$ (12 lbs), with a substantially worst performance in the fitting to the experimental data for higher applied forces. This comparison demonstrates the necessity to still use the 3-stage dynamic model to characterize the behavior of the BRFD, due to the device's backlash.

Finally, a comparison is made between the hysteretic behavior of the first generation MFD and the BRFD. Figs. 11a and 11b show the modeled force-displacement and force-velocity plots of the BRFD in terms of \% force, starting with an applied force of $35 \mathrm{~N}$ (13\%). For completeness, results from various applied forces are compared against the modeled dynamic behavior 
Table 4: Comparison of fitting RMSE (kN)

\begin{tabular}{lcccccccc}
\hline \multirow{2}{*}{$\begin{array}{l}\text { Force } \\
\text { applied force }\end{array}$} & \multicolumn{2}{c}{$0.05 \mathrm{~Hz}$} & \multicolumn{2}{c}{$0.1 \mathrm{~Hz}$} & \multicolumn{2}{c}{$0.2 \mathrm{~Hz}$} & \multicolumn{2}{c}{$0.5 \mathrm{~Hz}$} \\
\cline { 2 - 8 } & 3-stage & LuGre & 3-stage & LuGre & 3-stage & LuGre & 3-stage & LuGre \\
\hline $35 \mathrm{~N}$ & 5.96 & 15.4 & 6.98 & 13.3 & 8.81 & 21.1 & 14.3 & 29.3 \\
$53 \mathrm{~N}$ & 3.07 & 5.38 & 3.25 & 5.38 & 3.51 & 6.00 & 3.34 & 5.47 \\
$66 \mathrm{~N}$ & 4.54 & 44.5 & 2.80 & 40.7 & 2.45 & 55.1 & 4.00 & 100 \\
$133 \mathrm{~N}$ & 7.56 & 76.3 & 15.7 & 127 & 44.1 & 46.2 & 27.8 & 117 \\
$267 \mathrm{~N}$ & 5.56 & 115 & 9.56 & 58.9 & 12.0 & 40.5 & 22.7 & 126 \\
\hline
\end{tabular}

338 of the first-generation rotary damping system (the MFD) in Figs. 11c and 339 11d. The backlash region is indicated in Figs. 11a and 11c, along with the 340 dynamic range under its maximum applied force. The backlash of the BRFD 341 is reduced to $2 \mathrm{~mm}$, from $12 \mathrm{~mm}$ for the MFD, while the dynamic range is 342 increased from $5.55 \mathrm{kN}$ (MFD) to $79.0 \mathrm{kN}$ (BRFD). This demonstrates that 343 the backlash effect has been substantially minimized, and that the BRFD is 344 capable of producing substantially higher damping force. 


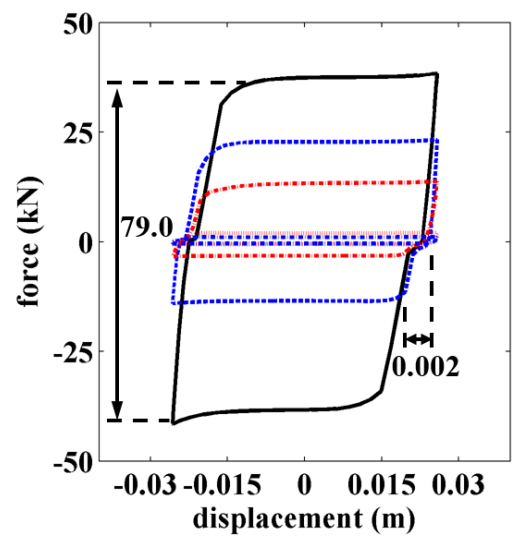

(a) BRFD force-displacement

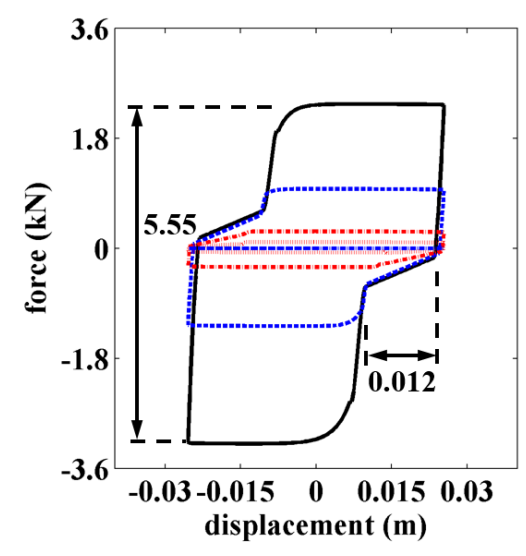

(c) MFD force-displacement

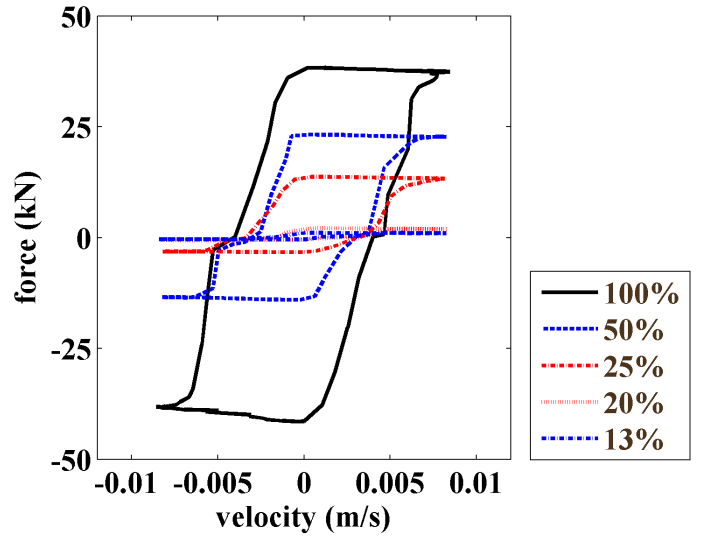

(b) BRFD force-velocity

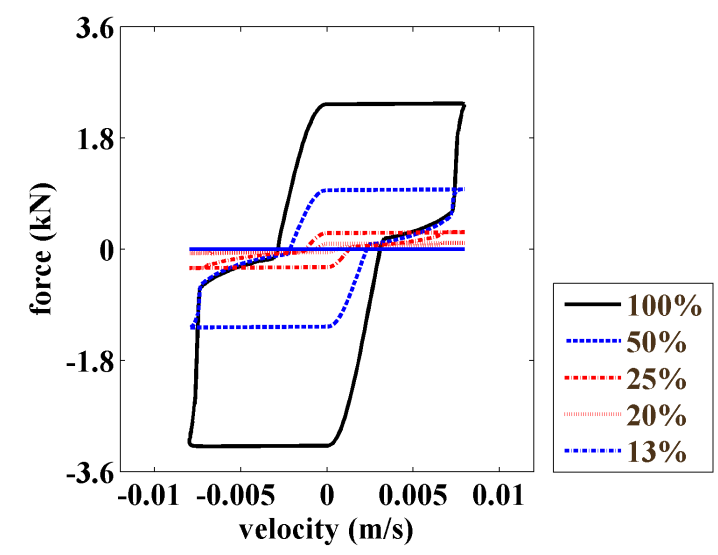

(d) MFD force-velocity

Figure 11: Modeled dynamics of the BRFD and MFD under various applied forces under a $0.05 \mathrm{~Hz}$ excitation of $25.4 \mathrm{~mm}$ ( 1 in) amplitude:

\subsection{Validation under Nonstationary Excitations}

The BRFD and its model are further validated using nonstationary excitations, consisting of two seismic excitations. The first excitation is the 1979 Imperial Valley earthquake record from USGS Station 5115 and the second 
the 1961 Hollister earthquake record from USGS station 1028. Ground displacements were computed by double integrating the ground acceleration obtained from the PEER ground motion database [42], and the maximum amplitude of each ground displacements is scaled to $0.01 \mathrm{~m}$ (0.4 in) to match the testing equipment's limitations. The BRFD was subjected directly to these displacement time-histories, as the purpose of the tests was to validate the model under nonstationary dynamics rather than validating damping characteristics within a structural system. Acceleration and scaled displacement time histories are shown in Fig. 12. 


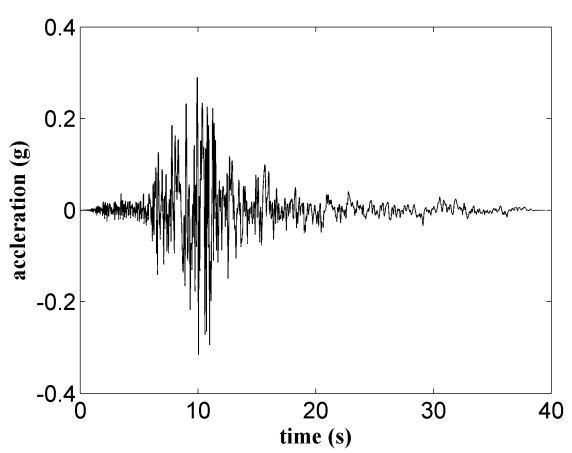

(a)

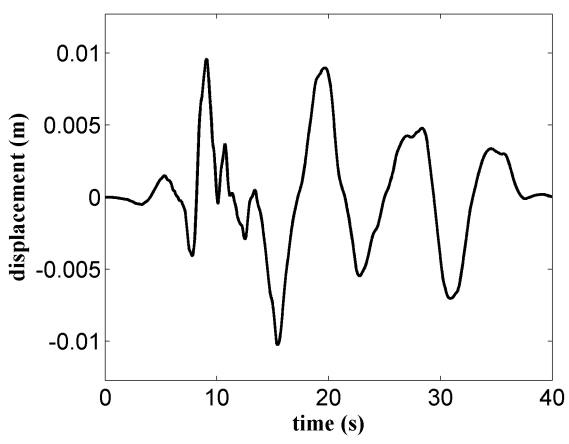

(c)

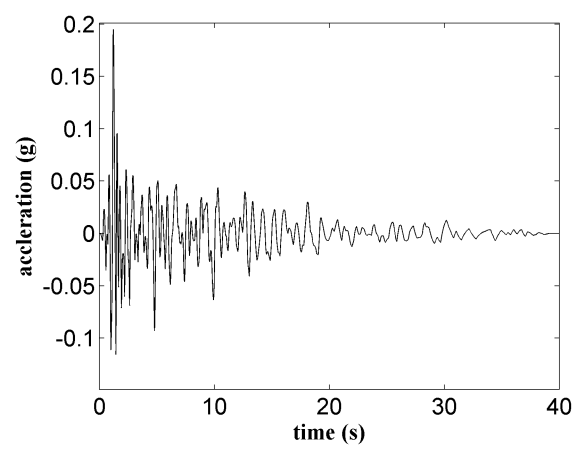

(b)

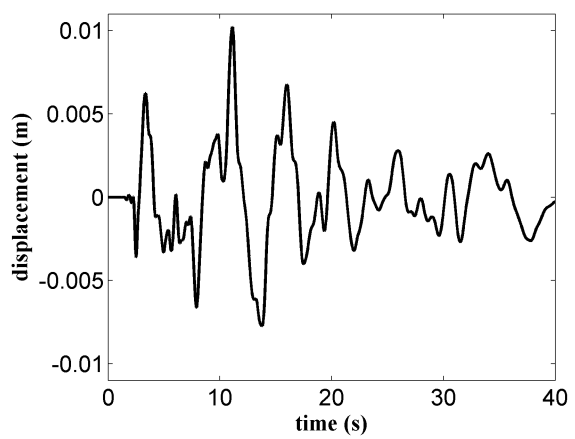

(d)

Figure 12: Earthquake excitations: (a) unscaled ground acceleration (Imperial Valley earthquake) ; (b) unscaled ground acceleration (Hollister earthquake); (c) scaled ground displacement (Imperial Valley earthquake); and (d) scaled ground displacement (Hollister earthquake).

The device is tested under two applied forces: $66 \mathrm{~N} \mathrm{(15} \mathrm{lb)} \mathrm{and} 133$ $\mathrm{N}$ (30 lb). Fig. 13 to 16 show the time history, force-displacement, and force-velocity plots for each seismic excitation. There is a good match of the theoretical model with the experimental data for both applied forces. A matching discrepancy is clearly observable under the Hollister earthquake 
363 at around $25 \mathrm{sec}$ (Fig. 15(a) and Fig. 16(a)). This is due to linear ap364 proximation of the damping force during a change in the rotational direction 365 of the drum where backlash is present. This overshoot is also present in 366 the Imperial Valley response, and can be observed at a small magnitude at 367 around $14 \mathrm{sec}$. This phenomenon will require further investigation, but its 368 effect could be reduced through the production of a high fidelity prototype. 369 Results from this section demonstrate that the BRFD behaves as designed 370 under nonstationary excitations. 


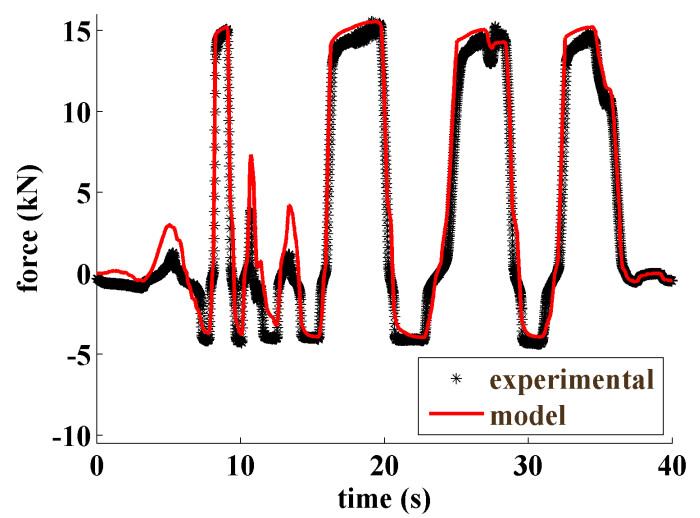

(a)

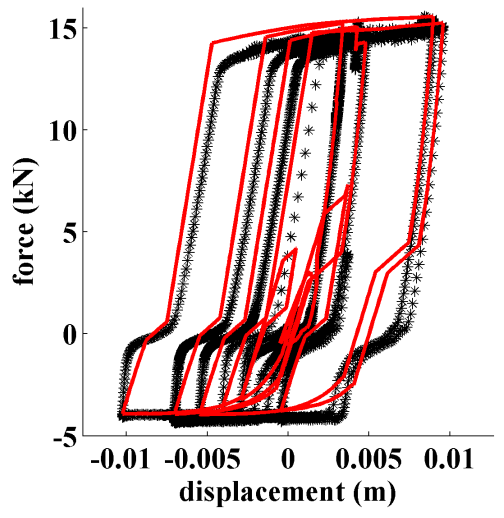

(b)

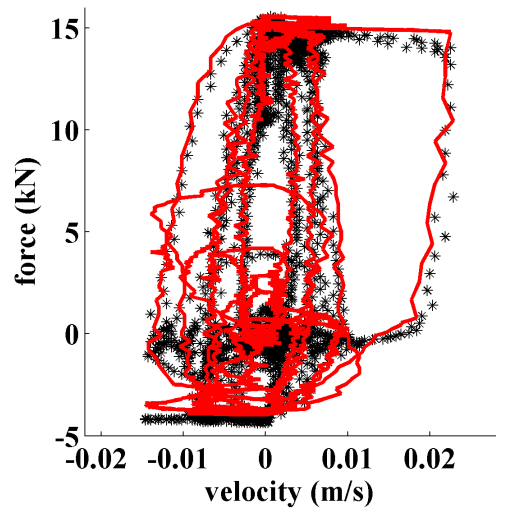

(c)

Figure 13: Imperial Valley earthquake at $66 \mathrm{~N}$ (15 lb): (a) time history of damping force; (b) force-displacement loop ; and (c) force-velocity loop. 


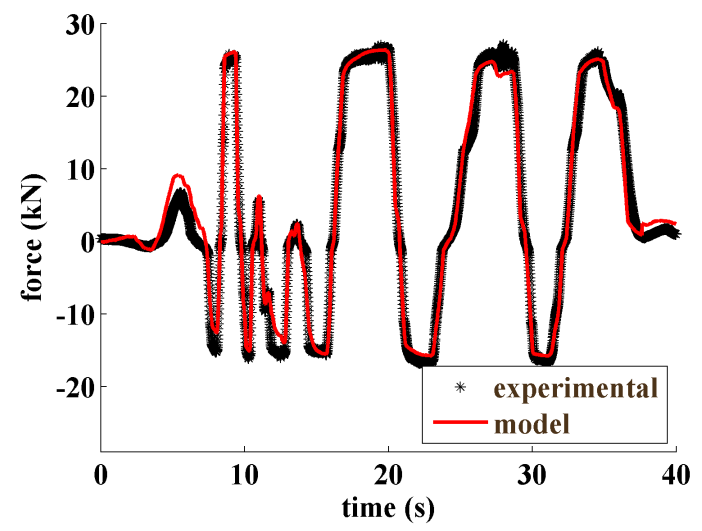

(a)

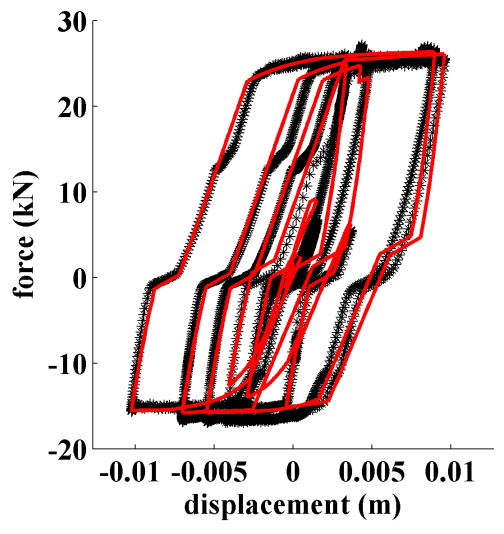

(b)

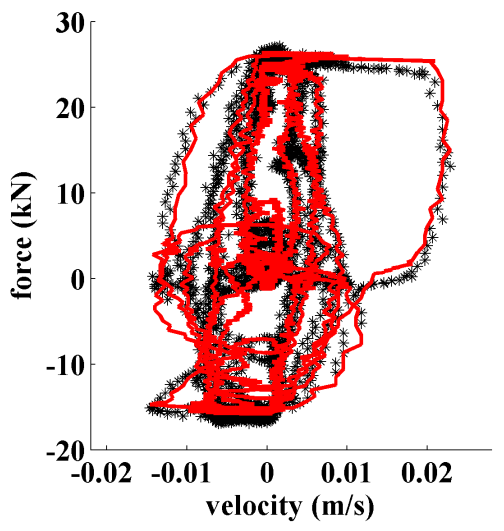

(c)

Figure 14: Imperial Valley earthquake at $133 \mathrm{~N}$ (30 lb): (a) time history of damping force ; (b) force-displacement loop ; and (c) force-velocity loop. 


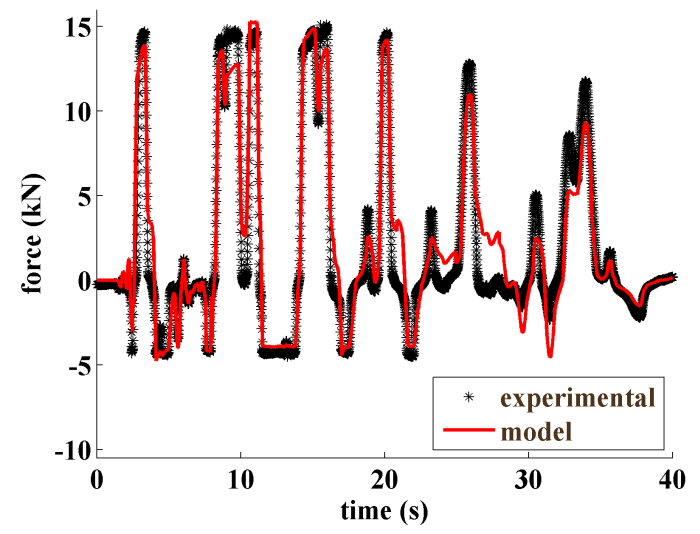

(a)

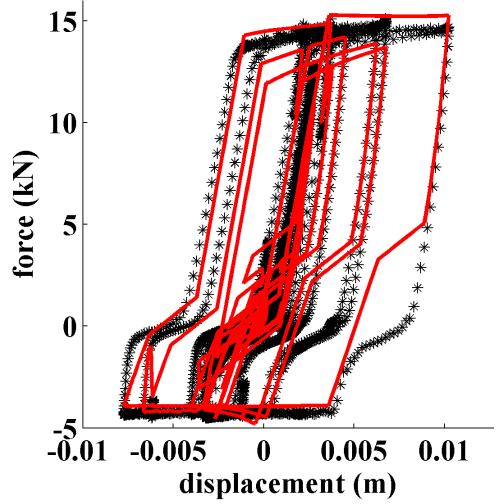

(b)

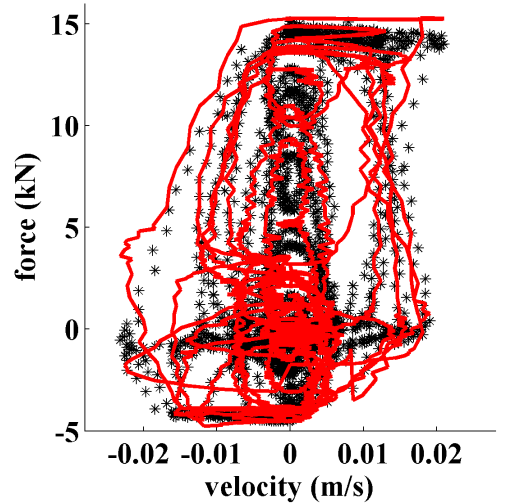

(c)

Figure 15: Hollister earthquake at $66 \mathrm{~N}(15 \mathrm{lb})$ : (a) time history of damping force ; (b) force-displacement loop ; and (c) force-velocity loop. 


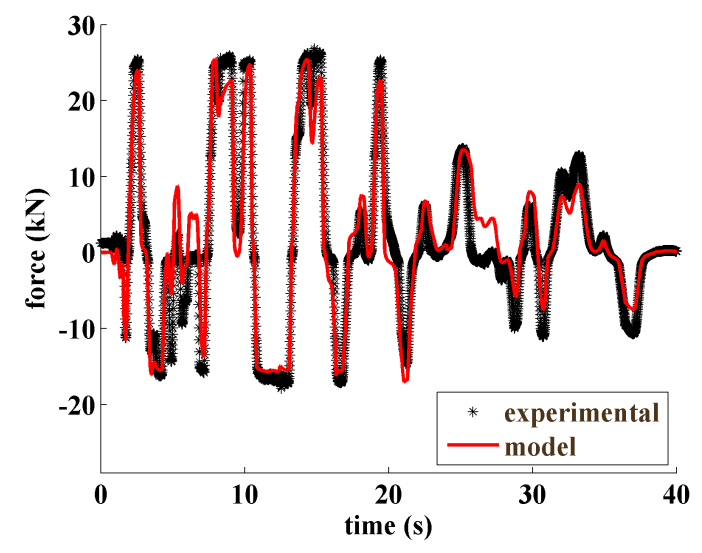

(a)

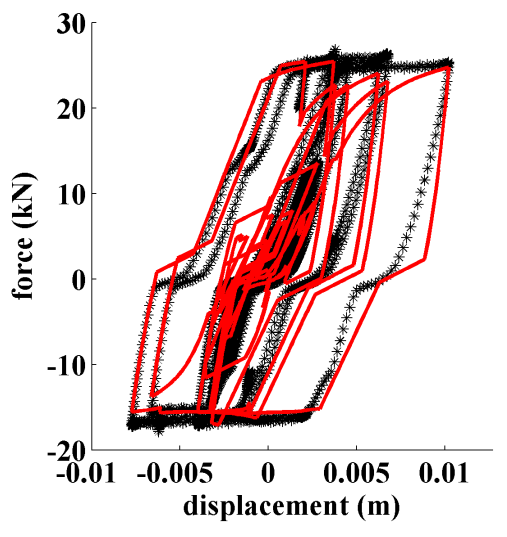

(b)

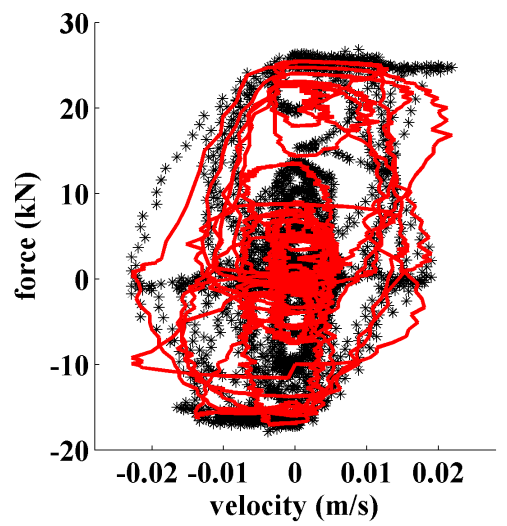

(c)

Figure 16: Hollister earthquake at $133 \mathrm{~N}$ (30 lb): (a) time history of damping force ; (b) force-displacement loop ; and (c) force-velocity loop.

\section{Summary and Conclusions}

In this paper, a novel variable friction damper for structural control applications was presented. The device, termed Banded Rotary Friction Device (BRFD), is based on the well-accepted and mature band brake technology. This makes the BRFD a mechanically robust, semi-active damping system. 
It is capable of providing large damping forces with a substantially lower applied force due to its positive servo effect.

A prototype of the BRFD was fabricated and experimentally validated. The dynamic tests were conducted under harmonic loads at different frequencies and applied forces. Results show that the prototype BRFD is capable of producing a maximum $45 \mathrm{kN}$ (10 kips) damping force. A 3-stage dynamic model was introduced and model parameters were identified based on test results. Results show that the model could be used to accurately model the dynamic behavior of the device. The experimental mechanical advantage demonstrates that the device was capable of a force amplification in the range of 125-150 times the applied force. These numbers show agreement with theoretical values. The proposed device and its model are further validated using nonstationary excitations consisting of two earthquake time series. Results demonstrated that the BRFD behaves as designed under nonstationary excitations.

The validated prototype and friction model presented in this research advances the potential for the implementation of semi-active friction devices. The BRFD is the second generation of rotary damping systems designed by the authors. It was specifically engineered to minimize the backlash effect and increase the maximum damping force by an order of magnitude. Results showed that the BRFD's has been successful at attaining both objectives, therefore making it a mechanically robust device capable of high variable friction force. 


\section{Acknowledgement}

This material is based upon work supported by the National Science Foundation under Grant no. 1300960. Their support is gratefully acknowledged. Any opinions, findings, and conclusions or recommendations expressed in this material are those of the authors and do not necessarily reflect the views of the National Science Foundation.

\section{References}

[1] B. Spencer Jr, S. Nagarajaiah, State of the art of structural control, Journal of structural engineering (2003).

[2] M. Symans, F. Charney, A. Whittaker, M. Constantinou, C. Kircher, M. Johnson, R. McNamara, Energy dissipation systems for seismic applications: current practice and recent developments, Journal of structural engineering 134 (2008) 3-21.

[3] J. J. Connor, S. Laflamme, Structural Motion Engineering, Springer, 2014.

[4] T. E. Saaed, G. Nikolakopoulos, J.-E. Jonasson, H. Hedlund, A stateof-the-art review of structural control systems, Journal of Vibration and Control 21 (2015) 919-937.

[5] Y. Liu, H. Matsuhisa, H. Utsuno, Semi-active vibration isolation system with variable stiffness and damping control, Journal of sound and vibration 313 (2008) 16-28. 
[6] W. He, A. Agrawal, K. Mahmoud, Control of seismically excited cablestayed bridge using resetting semiactive stiffness dampers, Journal of Bridge Engineering 6 (2001) 376-384.

[7] J. Yang, J. Bobrow, F. Jabbari, J. Leavitt, C. Cheng, P. Lin, Fullscale experimental verification of resetable semi-active stiffness dampers, Earthquake engineering \& structural dynamics 36 (2007) 1255-1273.

[8] O. Yoshida, S. J. Dyke, Seismic control of a nonlinear benchmark building using smart dampers, Journal of engineering mechanics 130 (2004) 386-392.

[9] B. Spencer Jr, S. Nagarajaiah, State of the art of structural control, Journal of structural engineering 129 (2003) 845-856.

[10] T. Vesselenyi, S. Dzitac, I. Dzitac, M.-J. Manolescu, Fuzzy and neural controllers for a pneumatic actuator, International Journal of Computers, Communications and Control 2 (2007) 375-387.

[11] A. Mehmood, S. Laghrouche, M. El Bagdouri, Modeling identification and simulation of pneumatic actuator for vgt system, Sensors and Actuators A: Physical 165 (2011) 367-378.

[12] S. Kannan, H. M. Uras, H. M. Aktan, Active control of building seismic response by energy dissipation, Earthquake engineering \& structural dynamics 24 (1995) 747-759.

[13] M. Lorenz, B. Heimann, V. Härtel, A novel engine mount with semiactive dry friction damping, Shock and Vibration 13 (2006) 559-571. 
[14] J. N. Yang, A. K. Agrawal, Semi-active hybrid control systems for nonlinear buildings against near-field earthquakes, Engineering Structures 24 (2002) 271-280.

[15] S. Narasimhan, S. Nagarajaiah, Smart base isolated buildings with variable friction systems: $\mathrm{H}$ controller and saivf device, Earthquake engineering \& structural dynamics 35 (2006) 921-942.

[16] Y. Kawamoto, Y. Suda, H. Inoue, T. Kondo, Electro-mechanical suspension system considering energy consumption and vehicle manoeuvre, Vehicle System Dynamics 46 (2008) 1053-1063.

[17] C. Chen, G. Chen, Shake table tests of a quarter-scale three-storey building model with piezoelectric friction dampers, Structural Control and Health Monitoring 11 (2004) 239-257.

[18] L.-Y. Lu, G.-L. Lin, A theoretical study on piezoelectric smart isolation system for seismic protection of equipment in near-fault areas, Journal of Intelligent Material Systems and Structures 20 (2009) 217-232.

[19] O. Durmaz, W. W. Clark, D. S. Bennett, J. S. Paine, M. N. Samuelson, Experimental and analytical studies of a novel semi-active piezoelectric coulomb damper, in: SPIE's 9th Annual International Symposium on Smart Structures and Materials, International Society for Optics and Photonics, 2002, pp. 258-273.

[20] Y. Xu, C. Ng, Seismic protection of a building complex using variable friction damper: experimental investigation, Journal of engineering mechanics 134 (2008) 637-649. 
[21] I. H. Mualla, B. Belev, Performance of steel frames with a new friction damper device under earthquake excitation, Engineering Structures 24 (2002) 365-371.

[22] J. Pardo-Varela, J. Llera, A semi-active piezoelectric friction damper, Earthquake Engineering \& Structural Dynamics 44 (2015) 333-354.

[23] H. Dai, Z. Liu, W. Wang, Structural passive control on electromagnetic friction energy dissipation device, Thin-Walled Structures 58 (2012) 1-8.

[24] S. Laflamme, et al., Control of large-scale structures with large uncertainties, Ph.D. thesis, Massachusetts Institute of Technology, 2011.

[25] T. L. Karavasilis, R. Sause, J. M. Ricles, Seismic design and evaluation of steel moment-resisting frames with compressed elastomer dampers, Earthquake Engineering \& Structural Dynamics 41 (2012) 411-429.

[26] Y. Chae, J. M. Ricles, R. Sause, Modeling of a large-scale magnetorheological damper for seismic hazard mitigation. part i: Passive mode, Earthquake engineering \& structural dynamics 42 (2013) 669-685.

[27] L. Cao, A. Downey, S. Laflamme, D. Taylor, J. Ricles, Variable friction device for structural control based on duo-servo vehicle brake: Modeling and experimental validation, J. Sound and Vibration (2015).

[28] Rauscher, Winch, 1922. US Patent 1,413,292.

[29] C. A. Johnson, L. H. Lucker Jr, Mooring apparatus for floating vessels, 1984. US Patent $4,446,807$. 
[30] D. S. Han, G. J. Han, D. H. Choi, A study on durability enhancement of band brake for mooring winch, in: Advanced Materials Research, volume 201, Trans Tech Publ, 2011, pp. 314-317.

[31] B. R. E. G. . Co., data sheet: Bermskerl 4500, 1640 Shanahan Drive, South Elgin, IL 60177., 2013.

[32] D. P. Taylor, Toggle brace dampers: A new concept for structural control, in: Advanced technology in structural engineering: Proc., 2000 Structures Congress and Exposition, 2000.

[33] M. C. Constantinou, P. Tsopelas, W. Hammel, A. N. Sigaher, Togglebrace-damper seismic energy dissipation systems, Journal of Structural Engineering 127 (2001) 105-112.

[34] A. K. Baker, Industrial brake and clutch design, Pentech Press, 1992.

[35] E. A. Avallone, T. Baumeister, A. M. Sadegh, Marks' standard handbook for mechanical engineers, volume 9, McGraw-Hill New York, 1996.

[36] H. Olsson, K. J. Åström, C. Canudas de Wit, M. Gäfvert, P. Lischinsky, Friction models and friction compensation, European journal of control 4 (1998) 176-195.

[37] F. Altpeter, Friction modeling, identification and compensation (1999).

[38] C. C. De Wit, P. Lischinsky, Adaptive friction compensation with partially known dynamic friction model, International journal of adaptive control and signal processing (1998) 65-80. 
509

510

511

512

513

514

515

517

518

[39] A. Shiriaev, A. Robertsson, R. Johansson, Friction compensation for passive systems based on the lugre model, in: Lagrangian and Hamiltonian Methods for Nonlinear Control 2003: A Proceedings Volume from the 2nd IFAC Workshop, Seville, Spain, 3-5 April, 2003, Elsevier, 2003, p. 159.

[40] P. Lischinsky, C. Canudas-de Wit, G. Morel, Friction compensation for an industrial hydraulic robot, Control Systems, IEEE 19 (1999) 25-32.

[41] S. Laflamme, J. Slotine, J. Connor, Wavelet network for semi-active control, Journal of Engineering Mechanics 137 (2011) 462-474.

[42] PEER, Peer, pacific earthquake engineering research center, 2010. 